\title{
A statistical assessment of tropical cyclone activity in atmospheric general circulation models
}

\author{
By SUZANA J. CAMARGO*, ANTHONY G. BARNSTON and STEPHEN E. ZEBIAK, \\ International Research Institute for Climate Prediction, The Earth Institute of Columbia University, Lamont Campus, \\ Palisades, NY 10964-8000, USA
}

(Manuscript received 16 April 2004; in final form 15 November 2004)

\begin{abstract}
The properties of tropical cyclones in three low-resolution atmospheric general circulation models (AGCMs) in seven ocean basins are discussed. The models are forced by prescribed, observed sea surface temperatures over a period of $40 \mathrm{yr}$, and their simulations of tropical cyclone activity are compared with observations. The model cyclone characteristics considered include genesis position, number of cyclones per year, seasonality, accumulated cyclone energy, track locations, and number of storm days. Correlations between model and observed interannual variations of these characteristics are evaluated. The models are found able to reproduce the basic features of observed tropical cyclone behavior such as seasonality, general location and interannual variability, but with identifiable biases. A bias correction is applied to the tropical cyclone variables of the three models. The three AGCMs have different levels of realism in simulating different aspects of tropical cyclone activity in different ocean basins. Some strengths and weaknesses in simulating certain tropical cyclone activity variables are common to the three models, while others are unique to each model and/or basin. Although the overall skill of the models in reproducing observed interannual variability of tropical cyclone variables has not surpassed or often even equalled that of statistical models, there exists potential for higher future skills using improved versions of dynamical approaches.
\end{abstract}

\section{Introduction}

The possibility of using dynamical climate models to forecast seasonal tropical cyclone activity has been explored by various authors (e.g. Bengtsson et al., 1982; Vitart et al., 1997). Although low-resolution $\left(2^{\circ}-3^{\circ}\right)$ climate general circulation models (GCMs) are not adequate for forecasts of individual cyclones, they can have skill in forecasting seasonal tropical cyclone activity (Bengtsson, 2001). Presently, experimental dynamical forecasts of tropical cyclone activity are produced by several centers, including the European Centre for MediumRange Weather Forecasts (ECMWF; Vitart and Stockdale, 2001) and the International Research Institute for Climate Prediction (IRI; Experimental Tropical Cyclone Activity Forecasts available on-line at http://iri.columbia.edu/forecast/tc_fcst/). The effectiveness of dynamical climate models for forecasting tropical cyclone landfall over Mozambique has recently been analyzed (Vitart et al., 2003). Routine seasonal forecasts of tropical cyclone frequency in the Atlantic sector are produced using statistical methods by different institutions (Gray et al., 1993, 1994; see also the Climate Prediction Cen-

\footnotetext{
* Corresponding author.

e-mail: suzana@iri.columbia.edu
}

ter, on-line at http://www.cpc.noaa.gov/products/, and Tropical Storm Risk, on-line at http://tropicalstormrisk.com/). Statistical seasonal forecasts of tropical cyclone frequency are also issued for the western North Pacific, eastern North Pacific, and Australian sectors (Chan et al., 1998; Liu and Chan, 2003; see also the Climate Prediction Center, on-line at http://www.cpc.noaa.gov/products/, and Tropical Storm Risk, on-line at http://tropicalstormrisk.com/).

A better understanding of the performance of different lowresolution atmospheric GCMs (AGCMs), under ideal circumstances of forcing by 'perfect' (observed) sea surface temperature (SST), is helpful in assessing the skill of these dynamical forecasts. In this paper, some basic characteristics of model tropical cyclones are examined in multidecadal simulations from three low-resolution global AGCMs. Previous studies of tropical cyclones in low-resolution AGCMs focused on single integrations (Bengtsson et al., 1995) or ensembles of a single model (e.g. Vitart et al., 1997) in a restricted time period (9 yr in Vitart et al., 1997; Vitart and Stockdale, 2001). Here we evaluate the performance of three AGCMs in simulating tropical cyclone activity over a longer period (40 yr) and for larger ensemble sets (9-24 members per model).

Tropical cyclones in low-resolution AGCMs have been found to have characteristics similar to those observed (e.g. Manabe 
et al., 1970). The intensity of these model cyclones is much lower, and their spatial scale larger, than their observed counterparts, due to the low resolution (Bengtsson et al., 1995; Vitart et al., 1997). The climatology, structure and interannual variability of model tropical cyclones have been examined (Bengtsson et al., 1982, 1995; Vitart et al., 1997), as well as their relation to large-scale circulation (Vitart et al., 1999) and SST variability (Vitart and Stockdale, 2001). The characteristics of model tropical cyclone formation over the western North Pacific have also been studied (Camargo and Sobel, 2004). In many cases, the spatial and temporal distributions of model tropical cyclones are found to be similar to those of observed tropical cyclones (Bengtsson et al., 1995; Vitart et al., 1997; Camargo and Zebiak, 2002).

There are two primary methods of using AGCMs to forecast tropical cyclone activity. One approach is to analyze largescale variables known to affect tropical cyclone activity (Ryan et al., 1992; Watterson et al., 1995; Thorncroft and Pytharoulis, 2001). Another approach, and the one used here, is to detect and track cyclone-like structures in AGCMs and coupled oceanatmosphere models (Manabe et al., 1970; Bengtsson et al., 1982; Krishnamurti, 1988; Krishnamurti et al., 1989; Broccoli and Manabe, 1990; Wu and Lau, 1992; Haarsma et al., 1993; Bengtsson et al., 1995; Tsutsui and Kasahara, 1996; Vitart et al., 1997; Vitart and Stockdale, 2001; Camargo and Zebiak, 2002). These methods have also been used in studies of possible changes in tropical cyclone intensity due to global climate change using both AGCMs (Bengtsson et al., 1996; Royer et al., 1998; Sugi et al., 2002) and regional climate models (Walsh and Ryan, 2000).

The nature of tropical cyclone activity in AGCMs depends on various characteristics of the models, such as physical parametrizations and circulation. Therefore, the analysis of the tropical cyclone activity in different AGCMs provides a different diagnostic of the strengths and weaknesses of these AGCMs and could be used to improve future versions of these models.

This paper is organized as follows. A brief discussion of the data and methodology is given in Section 2. We examine global model climatologies of several parameters of tropical cyclone activity in Section 3, and the characteristics and skills of simulated interannual variability of these parameters by individual basin in Section 4. Conclusions are given in Section 5. A more detailed version of this paper appears as a technical report (Camargo et al., 2004).

\section{Data and methodology}

The AGCMs used in this study are ECHAM3.6 (here denoted ECHAM3), ECHAM4.5 (denoted ECHAM4), and NSIPP-1 (denoted NSIPP). The first two models were developed at the MaxPlanck-Institute for Meteorology, Hamburg, Germany (Model User Support Group, 1992; Roeckner et al., 1996) and the third model was developed at the National Aeronautics and Space Administration (NASA)/Goddard in Maryland, USA (NASA Seasonal to Interannual Prediction Project; Suarez and Takacs, 1995). The model integrations used in this study were performed using observed SST with the number of ensemble members, period and output frequency as shown in Table 1 . The resolution of both ECHAM models is T42 $\left(2.81^{\circ}\right)$ while the NSIPP model has a resolution of $2.5^{\circ} / 2^{\circ}$ longitude/latitude. These resolutions are used in the IRI operational seasonal forecasts (Mason et al., 1999; Goddard et al., 2001, 2003; Barnston et al., 2003). The model integrations of both ECHAM models were performed at IRI, while the NSIPP integrations were performed at NASA/Goddard.

Both ECHAM models have a parametrization of cumulus convection based on the bulk mass flux concept of Tiedtke (1989); however, a modified version of this parametrization was used in ECHAM4 (Roeckner et al., 1996). The NSIPP model convection parametrization uses the relaxed Arakawa-Shubert scheme (Moorthi and Suarez, 1992).

Although a longer period of integrations for some of the models is available, we restrict the analysis to the common period of 1961-2000. The observational data used are from the Best Track data sets. The Southern Hemisphere, Indian Ocean, and western North Pacific data are from the Joint Typhoon Warning Center Best Track data set (available on-line at http:// metoc.npmoc.navy.mil/jtwc/best_tracks/), while the eastern North Pacific and Atlantic data are from the National Hurricane Center Best Track data set (available on-line at http:// www.nhc.noaa.gov/pastall.shtml). From the observed data sets, only tropical cyclones with tropical storm or typhoon intensity are considered for the model comparison, i.e. tropical depressions (not named) are not included.

In the pre-satellite years (1960s), some tropical cyclones could have escaped detection, and therefore are not included in the the Best Track data sets. All our statistical analyses were performed both for the whole period (1961-2000) and for the satellite era (1971-2000), with no significant differences other than slightly

Table 1. Simulation properties and characteristics of the AGCMs

\begin{tabular}{lccc}
\hline Model & ECHAM3 & ECHAM4 & NSIPP \\
\hline Period & $1961-2000$ & $1961-2000$ & $1961-2000$ \\
Ensemble size & 10 & 24 & 09 \\
Output type & Six-hourly & Six-hourly & Daily \\
Resolution & T42 (spectral) & T42 (spectral) & $2.5^{\circ} \times 2^{\circ}$ (grid point) \\
Convection scheme & Mass flux - Tiedtke & Modified mass flux - Tiedtke & Relaxed Arakawa-Shubert \\
\hline
\end{tabular}


Fig 1. Definition of the ocean basin domains used in this study: South Indian (SI), 30-105E; Australian (AUS), 105E-165E; South Pacific (SP), 165E-110W; North Indian (NI), 45E-100E; western North Pacific (WNP), 100E-160W; eastern North Pacific (ENP), 160W-100W; Atlantic (ATL), 100W-0. All latitude boundaries are along the equator and $40^{\circ} \mathrm{N}$ or $40^{\circ} \mathrm{S}$. Note the unique boundary paralleling Central America for ENP and ATL basins.

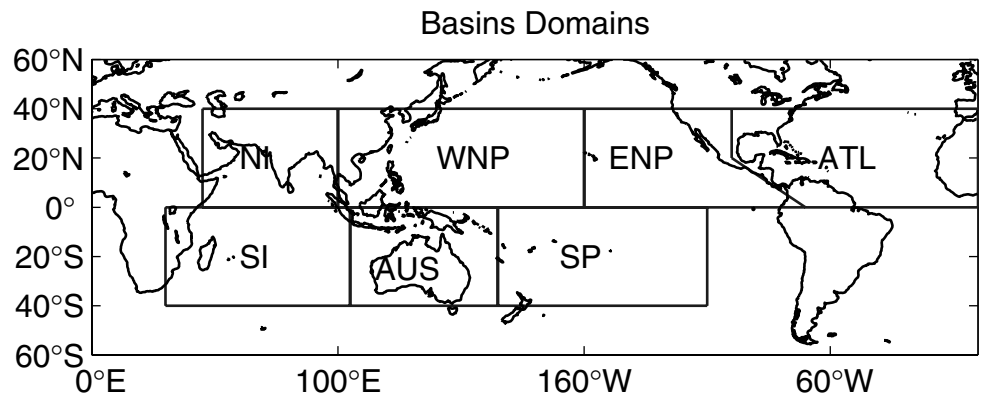

better skill results in the latter period, especially in the Southern Hemisphere.

To obtain representative tropical cyclone frequency values in AGCMs, objective algorithms for detection and tracking of individual model tropical cyclones were developed (Camargo and Zebiak, 2002), based substantially on prior studies (Bengtsson et al., 1995; Vitart et al., 1997). The algorithm has two parts. In the detection part, storms that meet environmental and duration criteria are identified. A model tropical cyclone is identified when chosen dynamical and thermodynamical variables exceed thresholds based on observed tropical storm climatology. Most studies (Bengtsson et al., 1982; Vitart et al., 1997) use a single set of threshold criteria globally; however, these do not take into account model biases and deficiencies. We use basin- and modeldependent threshold criteria, based on the model climatology at each ocean basin, yielding better simulation of the seasonal cycle and interannual variability (Camargo and Zebiak, 2002). In the tracking part, disturbance tracks are obtained from the vorticity centroid, which defines the center of the tropical cyclone, and relaxed criteria. The detection and tracking algorithms detailed in that study have been applied to more localized tropical cyclone studies using regional climate models and reanalysis data (Landman et al., 2005), and are applied to the AGCMs used in the present study.

The definitions of the basins used here for the formation regions of the tropical cyclones are shown in Fig. 1. When the whole life cycle of the cyclones is considered, the poleward latitude limit is eliminated. Model biases in the mean and the distributional features of the tropical cyclone activity variables analyzed are treated individually by model and by basin. The distribution of the observed variable per year over the 40-yr period is compared with the model distributions, using all model ensemble members. Values corresponding to each tenth percentile are identified across the two distributions, and the model values are 'corrected' to the observed values. Values between decile locations in the models are treated using bilinear interpolation, and extrapolation is applied for the two tails ( $<10$ and $>90$ percentiles). The resulting modified model distributions not only have means and standard deviations very similar to those observed, but their higher moments also become similar (except for the extreme tails). The broad features of the patterns of the models' interannual variability are not appreciably affected by the bias correction. In most figures, the results shown are not bias-corrected; figures with bias-corrected variables are identified in their captions.

\section{Model climatology}

It is fundamental to know whether the models generate tropical cyclones in the regions and during the seasons in which they are observed in nature. In this section we examine model climatologies of genesis location, tracks, intensities and lifetimes.

\subsection{Genesis location}

In Fig. 2 the locations of tropical cyclone formation from one selected ensemble member of each model are shown for the 19612000 period, along with the observed first positions. Although only one of the ensemble members is shown, characteristics are sufficiently representative of the same analysis for the ensemble mean. The three models have differing biases in location and amount of tropical cyclone formation. However, all models are seen to have deficient formation in the Atlantic basin, particularly in the Caribbean and Gulf of Mexico. The models form a few tropical cyclones over land, as for example in ECHAM3 over western Africa. ${ }^{1}$

The distribution of first positions, using all ensemble realizations of the models, is expressed in terms of a frequency of storm genesis for each $4^{\circ}$ latitude or longitude interval, normalized by the number of years (40) and number of ensemble members for each model (Fig. 3). The zonal and meridional averages indicate a clear overall deficit in number of model cyclones formed. Figure 3a shows an equatorward bias in all models' tropical cyclone formation, with maximum between $8^{\circ}$ and $12^{\circ}$ from the equator and a rapid falloff with increasing latitude. The observed maximum occurs at $12^{\circ}$, with a more gradual decrease with latitude, especially in the North Atlantic.

\footnotetext{
${ }^{1}$ Our interpretation is that in ECHAM3 these represent easterly waves, which are mixed with (and indistinguishable from) the model's lowintensity tropical cyclones.
} 


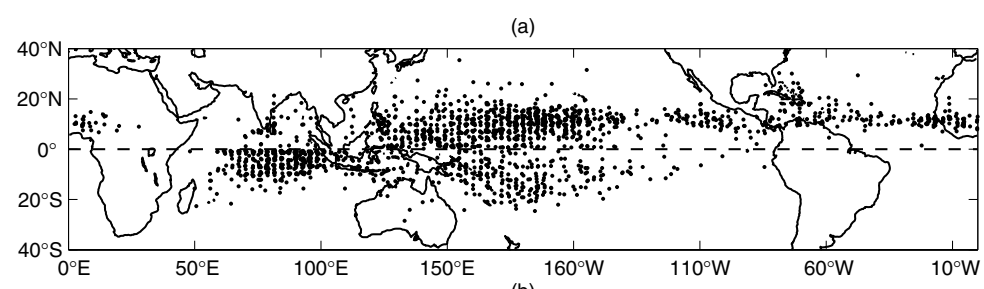

(b)
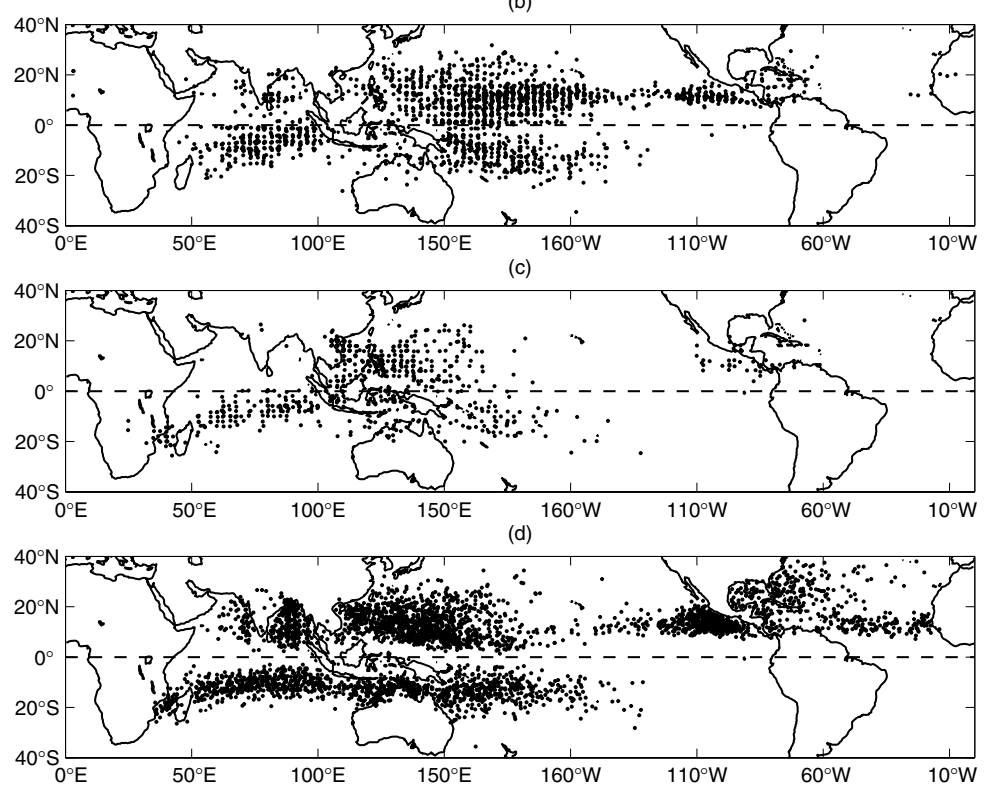

(a)

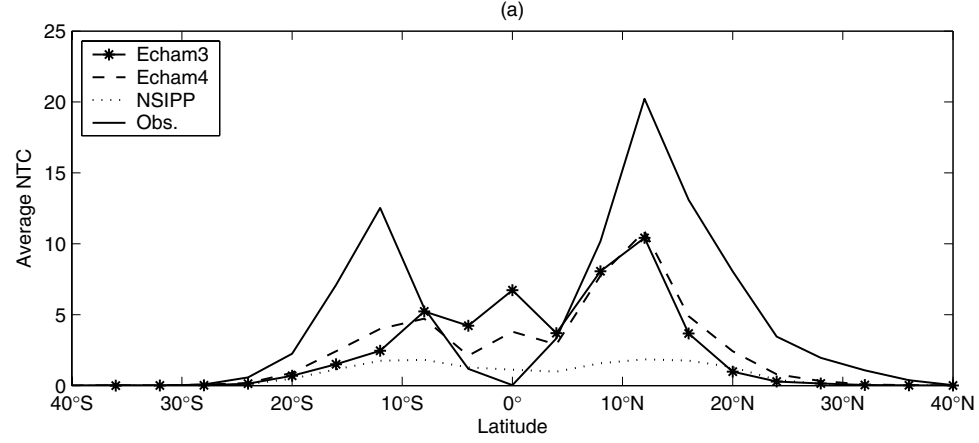

(b)

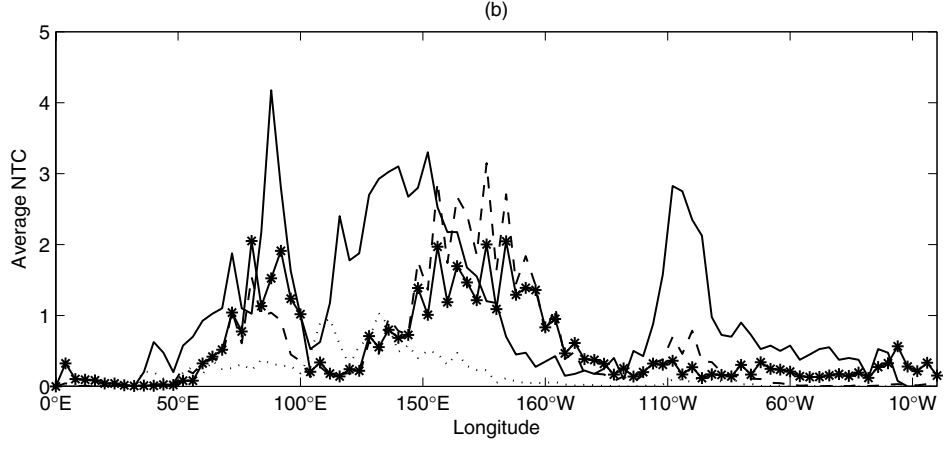

Fig 2. Location of model tropical cyclone formation in one ensemble member of (a) ECHAM3, (b) ECHAM4, and (c) NSIPP models, and in (d) observed names tropical cyclones. The period of coverage is 1961-2000.
Fig 3. Mean number of tropical cyclones by formation position per year and ensemble member per $4^{\circ}$ of (a) latitude (averaged over all longitudes) and (b) longitude (averaged over all latitudes), for the models (ECHAM3, dot-dashed line; ECHAM4, dashed line; NSIPP, dotted line) and observations (continuous line) over the period 1961-2000. 
Figure $3 \mathrm{~b}$ shows an eastward bias of both ECHAM models in the western Pacific. Also evident is a marked deficiency of model cyclones formed over the eastern Pacific and Atlantic. ECHAM4 has the most realistic number of tropical cyclones in the western North Pacific. While ECHAM3 has the most realistic density of formation in the Indian Ocean, it occurs mainly near the equator rather than in two separate bands on either side of the equator. The NSIPP model has a realistic formation concentration near the Maritime continent and Australia, as well as between Madagascar and Africa. None of the models forms tropical cyclones over the South Atlantic, which did occur in numerous previous studies (Broccoli and Manabe, 1990; Wu and Lau, 1992; Haarsma et al., 1993; Tsutsui and Kasahara, 1996; Vitart et al., 1997). South Atlantic hurricanes are very rare, but they do occur occasionally (Emanuel, 2003). For instance, in late March 2004 a cyclone (Catarina) formed near the Brazil coast, spawning controversy concerning its tropical character.

The correspondences between the model and observed spatial distributions of formation location was quantified using spatial correlation and mean square error. The NSIPP model has the highest global spatial correlation, while ECHAM4 has the lowest mean square error. All three models are more skillful in the Southern Hemisphere than in the Northern Hemisphere, due to their ability to roughly reproduce formation in the southern Indian and western South Pacific oceans.

The mean and standard deviation of the number of tropical cyclones (NTC) per year in the models and in observations are shown in Table 2 for each ocean basin, each hemisphere and the globe. The mean number of observed named tropical cyclones per year in the period 1961-2000 is 91.0. The ensemble means of the ECHAM3 and ECHAM4 models are approximately half of this value, while the NSIPP model's percentage is only $17 \%$. In observations, on average, $68 \%$ of the total NTC are in the Northern Hemisphere and $32 \%$ are in the Southern Hemisphere. All models correctly produce more tropical cyclones in the Northern Hemisphere than in the Southern Hemisphere.

In observations, the western North Pacific has the highest fraction of the global NTC, averaging 27.4 cyclones per year, or $30 \%$ of the global total (Table 2). All models reproduce this feature, but with an even higher contribution to the global total. The eastern North Pacific has the second highest NTC in observations; however, all three models produce proportionally few tropical cyclones there. The low resolution is likely one reason for deficient performance in this basin, as noted by Vitart et al. (1997) in the Geophysical Fluid Dynamics Laboratory (GFDL) AGCM. A large percentage of the eastern Pacific tropical cyclones are formed as easterly waves coming from the Atlantic across the Central America mountainous region (see, for example, Avila et al., 2003; Franklin et al., 2003), which is poorly represented in low-resolution AGCMs.

The Atlantic has very few tropical cyclones in the ECHAM4 and NSIPP models (Table 2). The ECHAM3 model is active in the Atlantic with $13 \%$ of the global NTC, compared with $11 \%$ in the observations (some, however, form over land in western Africa). In contrast, in ECHAM4 and NSIPP form most Atlantic tropical cyclones in the Caribbean region. The region with most observed tropical cyclones in the Southern Hemisphere is the South Indian Ocean, followed by the Australian region and the South Pacific. The only model whose NTC in the Southern Hemisphere has this order is the NSIPP model. This is analogous to, but less severe than, a bias of these models in forming tropical cyclones too far east in the western North Pacific.

Table 2. Mean, standard deviation (SD) and coefficient of variation (CV, or SD/mean) of NTC in all basins, Northern (NH) and Southern (SH) Hemispheres and globally (GL), with their respective percentage (Perc.) contribution to the global totals in models and observations (OBS.) in the period 1961-2000

\begin{tabular}{|c|c|c|c|c|c|c|c|c|c|c|c|c|c|c|c|c|}
\hline \multirow[b]{2}{*}{ Basin } & \multicolumn{4}{|c|}{ ECHAM3 } & \multicolumn{4}{|c|}{ ECHAM4 } & \multicolumn{4}{|c|}{ NSIPP } & \multicolumn{4}{|c|}{ OBS. } \\
\hline & Mean & SD & $\mathrm{CV}$ & Perc. & Mean & SD & $\mathrm{CV}$ & Perc. & Mean & $\mathrm{SD}$ & $\mathrm{CV}$ & Perc. & Mean & SD & $\mathrm{CV}$ & Perc. \\
\hline NI & 1.3 & 0.5 & 0.4 & $2.7 \%$ & 2.0 & 0.6 & 0.3 & $4.1 \%$ & 0.3 & 0.2 & 0.7 & $1.9 \%$ & 9.1 & 5.7 & 0.6 & $10.0 \%$ \\
\hline WNP & 17.8 & 5.1 & 0.3 & $36.6 \%$ & 23.9 & 3.1 & 0.1 & $49.5 \%$ & 7.4 & 2.1 & 0.3 & $47.2 \%$ & 27.4 & 4.9 & 0.2 & $30.1 \%$ \\
\hline ENP & 4.2 & 2.1 & 0.5 & $8.6 \%$ & 4.5 & 1.7 & 0.4 & $9.3 \%$ & 0.3 & 0.2 & 0.7 & $1.9 \%$ & 15.3 & 5.0 & 0.3 & $16.8 \%$ \\
\hline ATL & 6.3 & 1.6 & 0.2 & $13.0 \%$ & 2.2 & 0.6 & 0.3 & $4.6 \%$ & 0.6 & 0.4 & 0.7 & $3.8 \%$ & 10.0 & 3.4 & 0.3 & $11.0 \%$ \\
\hline $\mathrm{NH}$ & 29.6 & 5.8 & 0.2 & $60.9 \%$ & 32.6 & 3.6 & 0.1 & $67.5 \%$ & 8.6 & 2.1 & 0.2 & $54.8 \%$ & 61.8 & 8.4 & 0.1 & $67.9 \%$ \\
\hline SI & 11.1 & 2.6 & 0.2 & $22.8 \%$ & 6.7 & 1.4 & 0.2 & $13.9 \%$ & 3.8 & 1.6 & 0.4 & $24.2 \%$ & 12.9 & 3.9 & 0.3 & $14.2 \%$ \\
\hline AUS & 2.8 & 1.1 & 0.4 & $5.8 \%$ & 3.1 & 0.7 & 0.2 & $6.4 \%$ & 2.2 & 0.9 & 0.4 & $14.0 \%$ & 10.5 & 4.0 & 0.4 & $11.5 \%$ \\
\hline SP & 5.1 & 3.3 & 0.6 & $10.5 \%$ & 5.9 & 1.6 & 0.3 & $12.2 \%$ & 1.1 & 0.8 & 0.7 & $7.0 \%$ & 5.8 & 3.2 & 0.5 & $6.3 \%$ \\
\hline SH & 19.0 & 4.4 & 0.2 & $39.1 \%$ & 15.7 & 1.8 & 0.1 & $32.5 \%$ & 7.1 & 2.0 & 0.3 & $45.2 \%$ & 29.2 & 5.8 & 0.2 & $32.1 \%$ \\
\hline GL & 48.6 & 8.2 & 0.2 & $100 \%$ & 48.3 & 3.3 & 0.1 & $100 \%$ & 15.7 & 2.6 & 0.2 & $100 \%$ & 91.0 & 10.3 & 0.1 & $100 \%$ \\
\hline
\end{tabular}


(a)

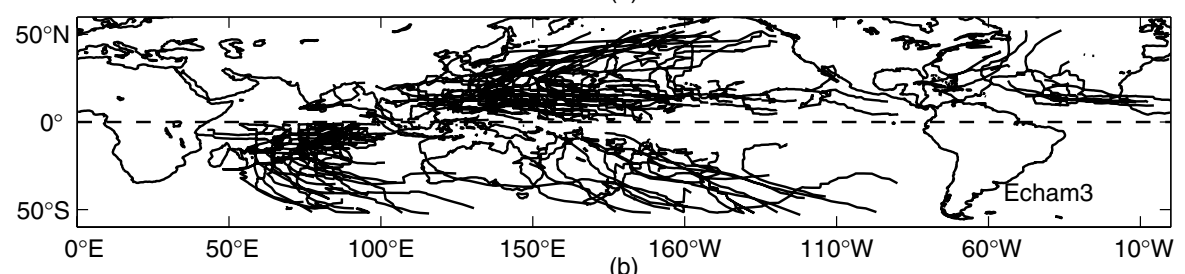

(b)
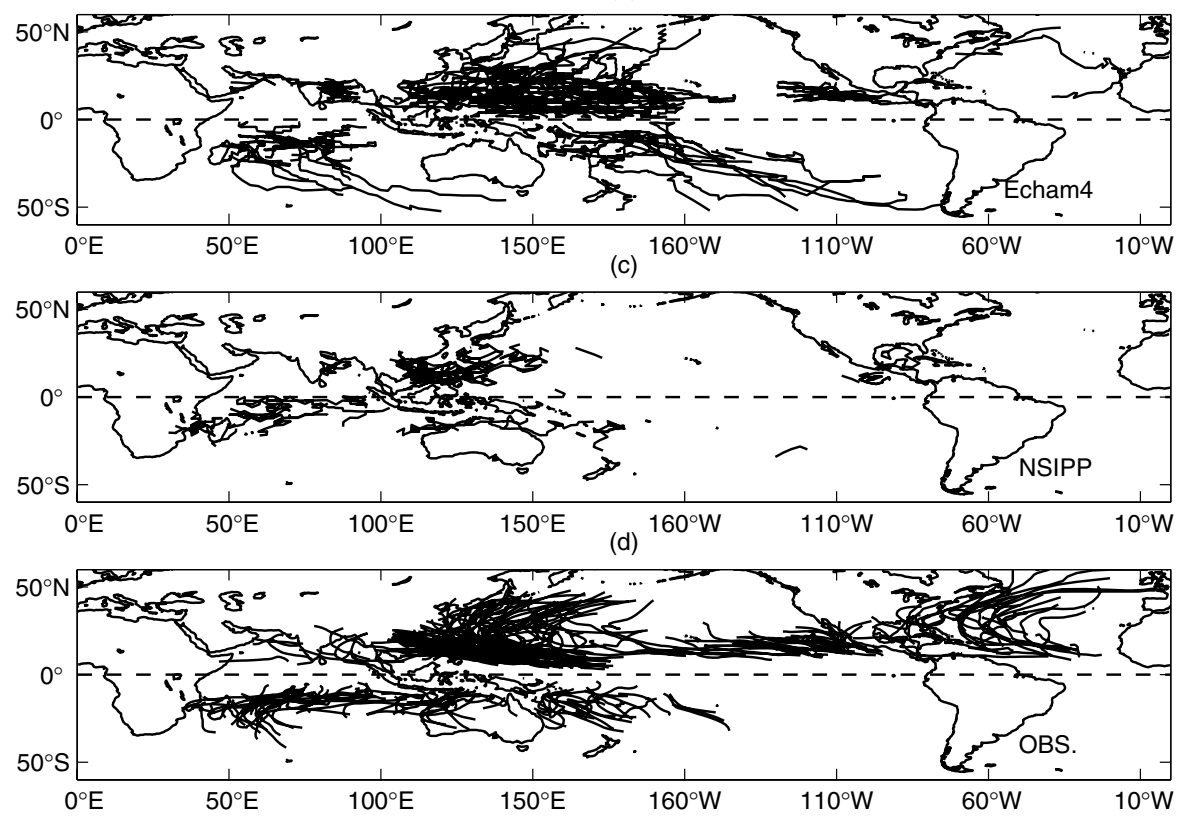

Fig 4. Tracks of tropical cyclones for the years 1993-1995 for that of the ensemble members in the models (a) ECHAM3, (b) ECHAM4, and (c) NSIPP, and (d) in the observations.

\subsection{Tracks, lifetimes and intensities}

In addition to frequency and geographical distribution of model tropical cyclone genesis, we look into the life cycle aspects of cyclone behavior: tracks, lifetimes, and intensities.

Figure 4 shows all the tropical cyclone tracks ${ }^{2}$ in one of the ensemble members of each of the models and in observations for the years 1993-1995. While the tracks vary among ensemble members, one ensemble member over a small number of years lacking an El Niño Southern Oscillation (ENSO) extreme provides an adequate sampling of the typical properties of the tracks.

In another study (Vitart et al., 1997), the tropical cyclone tracks in the GFDL GCM were found to be located somewhat more poleward, and to be shorter, than the observed tracks. A poleward

\footnotetext{
${ }^{2}$ Due to the low resolution, the tropical cyclone tracks are not as smooth as the observed ones, as the defined center of the tropical cyclone must 'jump' from one grid point to another, creating an apparent incremental distance that often is larger than that observed. The tracking algorithm does allow the storm center to be located between grid points, as the centroid of the vorticity to define the storm center. In spite of that, the storm centers still tend to 'jump' as the centroid will be nearer one grid point than nearer another adjacent one.
}

tendency is not evident in the AGCMs analyzed here (Fig. 4). This could be due to the differing tracking algorithms used here. In Vitart et al. (2003), the algorithm was slightly modified and applied to a different AGCM; this modification improved the realism of the tropical cyclone tracks. The different characteristics of AGCM tracks could be due to model differences and/or to the tracking algorithms.

In observations, the tropical cyclone tracks in the Southern Hemisphere are confined to a belt between $10^{\circ} \mathrm{S}$ and $40^{\circ} \mathrm{S}$ with occasional observed excursions south of $40^{\circ} \mathrm{S}$ (Fig. 4). In both ECHAM3 and ECHAM4, many tropical cyclones reach latitudes as far south as $50^{\circ} \mathrm{S}$. On the other hand, the tracks of the NSIPP model are shorter than those observed.

A more comprehensive view of the density of tracks is provided in Fig. 5. The track density is shown as the number of track positions per $4^{\circ}$ latitude and longitude per year and per ensemble member. The correspondence between the observed track density pattern with each model is summarized in Table 3 using spatial correlation and mean square error, for each hemisphere and for the globe. The ECHAM4 model has the highest spatial correlations, and all models have slightly larger correlation coefficients in the Southern Hemisphere than in the Northern Hemisphere. Globally and in the Northern Hemisphere, ECHAM3 has the 
(a)
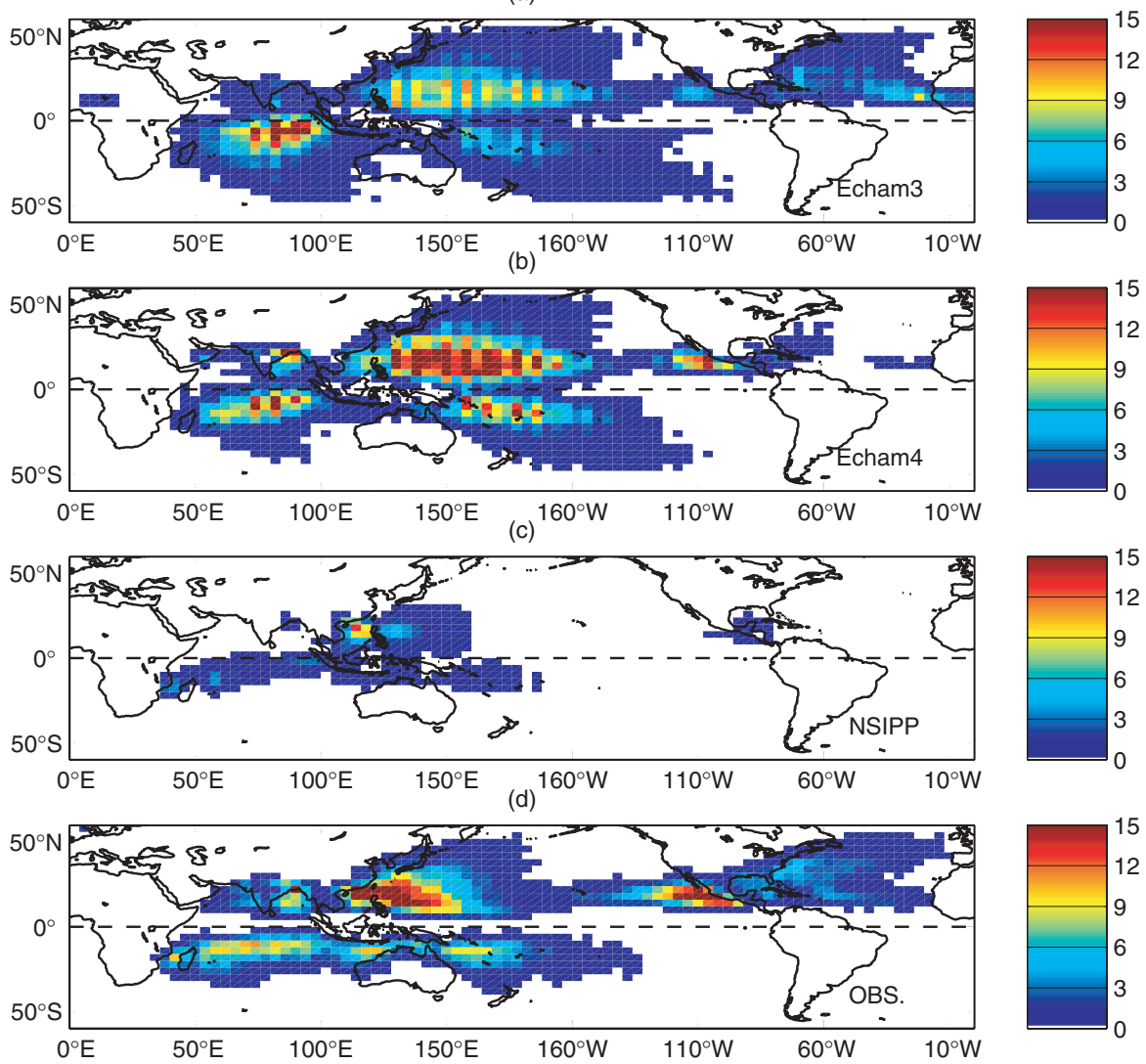

Fig 5. Tropical cyclone track density per year for the models (per ensemble member) (a) ECHAM3, (b) ECHAM4, and (c) NSIPP, and (d) for the observations, in the period 1961-2000.

Table 3. Correlations (Cor.) and mean square error (MSE; $\times 10^{-2}$ ) of track density per year per ensemble member (Fig. 5) in models versus observations: globe (GL), Northern Hemisphere (NH) and Southern Hemisphere ( $\mathrm{SH})$. Bold entries indicate correlation values having significance at the $95 \%$ confidence level

\begin{tabular}{lcccccccc}
\hline & \multicolumn{2}{c}{ ECHAM3 } & & \multicolumn{2}{c}{ ECHAM4 } & & \multicolumn{2}{c}{ NSIPP } \\
\cline { 2 - 3 } Model & Cor. & MSE & & Cor. & MSE & & Cor. & MSE \\
\hline GL & $\mathbf{0 . 5 5}$ & 2.8 & & $\mathbf{0 . 6 6}$ & 3.0 & & $\mathbf{0 . 5 2}$ & 3.0 \\
NH & $\mathbf{0 . 5 6}$ & 4.5 & & $\mathbf{0 . 6 4}$ & 5.2 & & $\mathbf{0 . 5 1}$ & 5.0 \\
SH & $\mathbf{0 . 5 9}$ & 3.2 & & $\mathbf{0 . 7 0}$ & 2.8 & & $\mathbf{0 . 5 8}$ & 3.0 \\
\hline
\end{tabular}

smallest mean square error. The NSIPP track density is less realistic than its genesis location, as its tracks are shorter than the observed tracks (Fig. 4c).

The large domains used in Table 3 may mask substantial smaller-scale features of the pattern correspondences. The NSIPP model has its track density limited to smaller regions than in the observations, particularly in the Pacific Ocean. The ECHAM3 model has a fairly realistic track density pattern over the Atlantic despite surplus activity over western Africa and near the African coast, and too little activity in the Gulf of Mexico and
Table 4. Mean, interannual standard deviation, and coefficient of variation of lifetime (in days) of tropical cyclones in the globe (GL), Northern Hemisphere $(\mathrm{NH})$ and Southern Hemisphere $(\mathrm{SH})$ in models and observations in the period 1961-2000

\begin{tabular}{|c|c|c|c|c|c|c|c|c|c|}
\hline \multirow[b]{2}{*}{ Model } & \multicolumn{3}{|c|}{ GL } & \multicolumn{3}{|c|}{$\mathrm{NH}$} & \multicolumn{3}{|c|}{ SH } \\
\hline & Mean & SD & $\mathrm{CV}$ & Mean & SD & $\mathrm{CV}$ & Mean & SD & $\mathrm{CV}$ \\
\hline ECHAM3 & 12.8 & 0.5 & 0.04 & 12.1 & 0.5 & 0.04 & 13.9 & 0.7 & 0.05 \\
\hline ECHAM4 & 15.6 & 0.5 & 0.03 & 15.2 & 0.6 & 0.04 & 16.6 & 0.5 & 0.03 \\
\hline NSIPP & 21.0 & 2.2 & 0.10 & 23.7 & 3.3 & 0.14 & 18.2 & 2.0 & 0.11 \\
\hline OBS. & 7.3 & 1.3 & 0.18 & 7.2 & 1.4 & 0.19 & 7.5 & 1.2 & 0.16 \\
\hline
\end{tabular}

near the eastern USA coast. All three models have too much nearequatorial activity. To some extent, this may be symptomatic of the low resolution of the models, as some dynamical processes may be shared differentially among adjacent grid squares and diluted in their proper grid squares.

It is interesting to know whether the lifetimes of model tropical cyclones are a reasonable facsimile of the observed lifetimes. Table 4 shows the simulated and observed averages, standard deviations, and coefficients of variation of the lifetime of tropical 
Table 5. MACE mean $\left(\times 10^{4}\right)$, standard deviation $\left(\mathrm{SD} ; \times 10^{4}\right)$ and coefficient of variation $(\mathrm{CV}$, or $\mathrm{SD} / \mathrm{mean})$ per year for all basins

\begin{tabular}{|c|c|c|c|c|c|c|c|c|c|c|c|c|}
\hline \multirow[b]{2}{*}{ Basin } & \multicolumn{3}{|c|}{ ECHAM3 } & \multicolumn{3}{|c|}{ ECHAM4 } & \multicolumn{3}{|c|}{ NSIPP } & \multicolumn{3}{|c|}{ OBS. } \\
\hline & Mean & SD & $\mathrm{CV}$ & Mean & SD & $\mathrm{CV}$ & Mean & SD & $\mathrm{CV}$ & Mean & SD & $\mathrm{CV}$ \\
\hline NI & 0.8 & 0.3 & 0.4 & 2.8 & 0.8 & 0.3 & 0.1 & 0.1 & 1.0 & 6.1 & 3.2 & 0.5 \\
\hline WNP & 16.4 & 5.3 & 0.3 & 30.4 & 4.5 & 0.1 & 3.4 & 1.2 & 0.3 & 89.3 & 32.1 & 0.4 \\
\hline ENP & 2.1 & 1.1 & 0.5 & 2.9 & 0.8 & 0.3 & 0.1 & 0.1 & 1.0 & 31.5 & 17.6 & 0.6 \\
\hline ATL & 4.8 & 1.6 & 0.3 & 0.7 & 0.3 & 0.4 & 0.1 & 0.1 & 1.0 & 27.3 & 15.8 & 0.6 \\
\hline SI & 11.7 & 2.7 & 0.2 & 8.6 & 1.5 & 0.2 & 1.7 & 0.6 & 0.3 & 31.7 & 13.2 & 0.4 \\
\hline AUS & 2.4 & 1.3 & 0.5 & 3.1 & 0.8 & 0.3 & 0.5 & 0.3 & 0.6 & 17.9 & 6.9 & 0.4 \\
\hline SP & 7.1 & 7.0 & 1.0 & 8.9 & 3.1 & 0.3 & 0.3 & 0.3 & 1.0 & 13.4 & 10.5 & 0.8 \\
\hline
\end{tabular}

cyclones globally and in each hemisphere. The average tropical cyclone lifetimes of the models are larger than those observed, with NSIPP having the largest average lifetime, almost three times the observed lifetimes. In previous discussions it was noted that the NSIPP NTCs were considerably fewer than those of the other two models. We thus conclude that the NSIPP model has few, but long-lasting, cyclones. The tropical cyclone lifetimes depend on the definition of the start and end points, which in turn depend on somewhat arbitrary intensity thresholds in both model and observations. Therefore, these longer lifetimes could be a result of the tracking algorithm definitions. As the tropical cyclones of the models do not match the observed cyclones in intensity, these thresholds differ greatly. However, we did apply this tracking algorithm to reanalysis data in a few case studies (Landman et al., 2005) and obtained tracks with very similar lifetimes to those observed.

An index that has been increasingly used to measure tropical cyclone activity is the accumulated cyclone energy (ACE), defined by Bell et al. (2000). The ACE index gives a measure not only of the number of tropical cyclones, but also their lifetimes and particularly their intensities. The ACE index for a basin is defined as the sum of the squares of the estimated six-hourly maximum sustained surface wind speed in knots for all periods in which the tropical cyclones in the basin have either a tropical storm or hurricane intensity. When more than one storm is active simultaneously, the squared wind speeds of these storms are added to form the basin ACE index. Note that this is an aggregation of a quadratic measure, as it is intended to relate to kinetic energy, and thus destruction potential. As such, it is sensitive to the occurrence and lifetimes of intense tropical cyclones, as opposed to the prevalence of weaker or intermediate strength cyclones. Here we define a slightly modified index, the modified accumulated cyclone energy (MACE), to describe the tropical cyclone activity in the models and observations. In contrast to the ACE definition, the times when named tropical cyclones have only tropical depression intensity are also included. Tropical cyclones have tropical depression intensity if they have an organized cylonic structure but their sustained surface wind speed is less than 34 knots, and for the model cyclones if their vortic- ity is below thresholds defined in Camargo and Zebiak (2002). (We also define MACE in $\left(\mathrm{m}^{2} \mathrm{~s}^{-2}\right)$, while ACE has usually been defined in $(\mathrm{knots})^{2}$.) The reason for this slightly modified definition is that the tropical cyclones in the models are weak, and distinguishing between a tropical depression and a tropical storm intensity for the model tropical cyclones is not straightforward. By following the model and observation tropical cyclones at all times, including prior to and following their peak strength (while they are only depressions), we think that a better comparison between the simulations is possible.

In the North Indian Ocean and the Southern Hemisphere, the Best Track data sets have little data for wind speed before 1980. Therefore, in calculating the MACE, two different periods are considered. For the western North Pacific, eastern North Pacific, and Atlantic, MACE calculations use data for the full period of 1961-2000. However, for the North Indian Ocean and the Southern Hemisphere, MACE is considered for the shorter period of 1981-2000.

In Table 5 the MACE mean, standard deviation, and coefficient of variation are shown for all basins. Aside from the negative bias of all models due to the lack of intensification of the model tropical cyclones, the ECHAM3 and ECHAM4 model MACE coefficients of variation are proportionally smaller than those observed in most basins, while NSIPP has larger values than those observed (especially when its mean is very small).

An index commonly used to measure tropical cyclone season activity is the number of days with tropical cyclone activity, or TC days. TC days does not provide information about cyclone strength, or number of cyclones during active days. Globally, the ECHAM3 result virtually matches that of the observations (Camargo et al., 2004), while ECHAM4 has an excess of days and the NSIPP model has too few days. All models reproduce the observed feature of there being more days with tropical cyclone activity in the Northern Hemisphere than in the Southern Hemisphere, with the ECHAM4 model having the most realistic ratio.

One might reasonably question the necessity of examining all of the tropical cyclone variables (NTC, MACE, lifetime, TC days, and others), as done above, when many of them are 
(a)

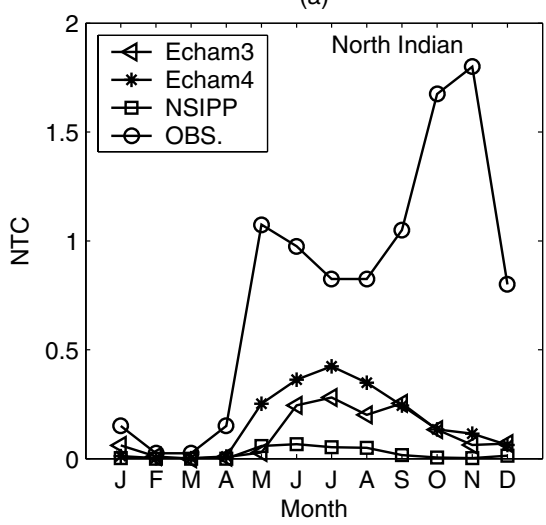

(c)

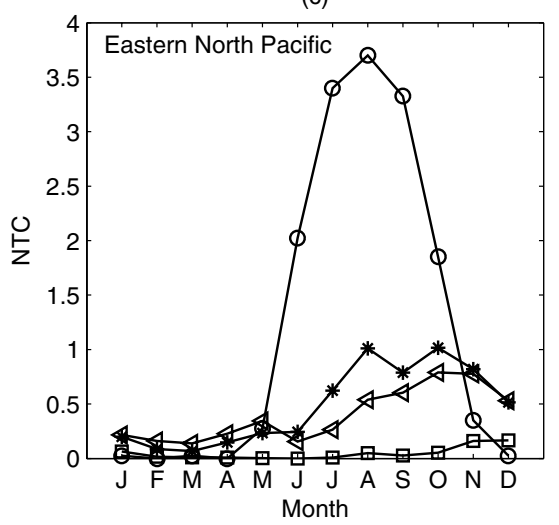

(b)

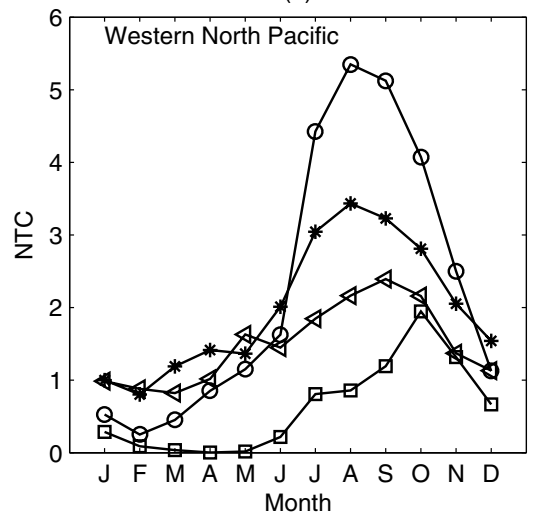

(d)

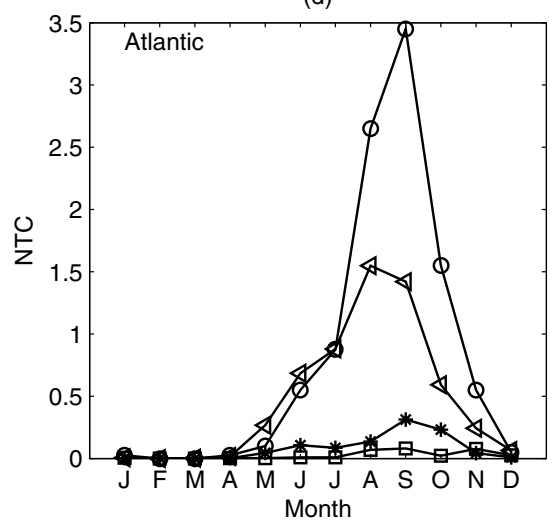

Fig 6. Average NTC per month in the models and observations in the period 1961-2000 in the Northern Hemisphere: (a) North Indian; (b) western North Pacific; (c) eastern North Pacific; (d) North Atlantic.

intercorrelated. A follow-on question would be whether any one (or two) of the variables would provide a sufficiently inclusive summary of the entire set. To help shed light on this issue, correlations among the four main variables listed above are examined for the globe, by hemisphere and by basin for the observations and the three models. ${ }^{3}$ Additionally, principal component (PC) analyses are performed using the correlation matrices as input. ${ }^{4}$ Our results (not shown) reveal that enough independent information is present in all variables to warrant attending to them, particularly when they may have differing implications with respect to the preservation of life and property.

Collectively, the analyses described in this section have shown that the models have many of the features of observed tropical cyclone behavior, although with clearly identifiable biases that vary with model and basin. Given the low resolution of the models, this result may be viewed as a favorable indication of what

\footnotetext{
${ }^{3}$ In forming the correlations, the square root of MACE is used to accommodate the linearity of the correlation and thereby maximize the potential strength of its relationships.

${ }^{4}$ In this PC analysis, the role often played by the grid points of a field is assumed here by the several tropical cyclone variables.
}

might be possible using these numerical tools. Even presently, biases do not necessarily preclude prognostic usability.

\section{Tropical cyclone activity characteristics and simulation skill}

In this section we explore the characteristics of the tropical cyclone activity by region and the extent of reproducibility of the observed interannual variabilities of the tropical cyclone variables in the three AGCMs forced by observed historical SST. The indicated levels of reproducibility imply the degree to which the models could be relied upon in real-time forecast settings. In gauging such possibilities, one must take into account that the SST itself would be predicted, so that expected skills would generally be lower than the upper limit as found here using observed (as if perfectly predicted) SST.

\subsection{Number of tropical cyclones}

The annual cycle of NTC per month for each basin of the Northern Hemisphere is shown in Fig. 6 in the three models and in observations. The month to which a tropical cyclone is attributed 
in this analysis is usually the same as the month of formation. However, when formation occurs during the last two days of a month, it is associated with the following month unless it dissipates within two days.

The observed annual cycle in the North Indian basin (Fig. 6a) has two peaks: one in May-June and a larger one in SeptemberDecember. The minimum in July and August is associated with the Indian summer monsoon. The ECHAM3 model has a slightly bimodal distribution with a weak relative minimum for August. In contrast, the peak NTC in the ECHAM4 model occurs during May-September (maximum in July), failing to recognize the mid-summer monsoonal hiatus. Although the Indian monsoon in both ECHAM3 (Lal et al., 1997; Arpe et al., 1998) and ECHAM4 (Cherchi and Navarra, 2003; May, 2003) has been analysed, the relation of model North Indian Ocean tropical cyclones to the Indian monsoon have not been explored.

The western North Pacific mean NTC per month (Fig. 6b) has an observed seasonality with a maximum in July-October, with tropical cyclones possible in all 12 months. The ECHAM4 and ECHAM3 average NTC is too small during the peak season (JASO) and proportionally too large in the early (MAMJ) and late (NDJF) seasons.

In the eastern North Pacific, the observed peak of the tropical cyclone activity occurs from July to September (Fig. 6c), with very few tropical cyclones occurring before June or after October. The three models are markedly deficient in tropical cyclone production in this basin, with ECHAM4 and ECHAM3 being relatively most active. The peak of NTC tends to occur late in all three models, although ECHAM4 performs best in this regard.

The Atlantic tropical cyclone peak season is August-October, with a maximum in September (Fig. 6d). ECHAM3 has a slightly early peak in August. ECHAM4 has a severe deficit in NTC, but a peak in August-October as in observations. ECHAM4 may have fewer tropical cyclones than ECHAM3 because the vertical wind shear in the tropical Atlantic in the ASO season is much greater in ECHAM4 than in ECHAM3. The NSIPP model has very few tropical cyclones in the North Atlantic.

Most of the tropical cyclones in the South Indian Ocean occur between December and March. The ECHAM3 model has a poorly defined annual cycle (not shown), with tropical cyclones present throughout the year and an unrealistic maximum from July to September. The ECHAM4 and NSIPP models have a more realistic annual cycle in the South Indian Ocean, but as in other basins, have too few tropical cyclones in the peak season. The Australian basin tropical cyclone peak season is during the austral summer (January-March) with a maximum in February. All models have low NTCs in this basin. Both ECHAM3 and ECHAM4 reproduce the peak in the correct season, with ECHAM3 having more tropical cyclones in the observed off-season. Both ECHAM3 and ECHAM4 have mean numbers of tropical cyclones in the South Pacific Ocean similar to those observed. The peak of the observed NTC season occurs in December-March, and both models peak then, but are phased slightly later. The NSIPP model has very few tropical cyclones in the South Pacific, although they are timed realistically.

The interannual variability of NTC in the western North Pacific in the models and observations is shown as a time series in Fig. 7a, where ensemble means are shown for the models. By eye, some positive correlation between the variability of the models and the observations is discernible. The spread of the ensemble members in ECHAM4 for the western North Pacific is given in Fig. 7b.

The correlations between model simulations and observations of NTC are shown in Table 6 for each of the basins. Only basins or models that have statistically significant correlations in at least one season are shown. Clearly, model skill for NTC is dependent on basin and season.

In evaluating significance, each year is assumed to contribute an independent sample. Examination of autocorrelation in the observations and in the model simulations at lags of 1-10 yr confirms the existence of approximate independence. An exception occurs in the North Indian Ocean, where there is a significant discontinuity in cyclone activity in the observations; however, the AGCMs do not reproduce this feature, making a reduction in the statistical degrees of freedom unnecessary.

The two basins with the highest skills for NTC are the Atlantic and South Pacific, largely due to a strong relationship with the ENSO. ECHAM4 has significant skill for NTC in the South Indian Ocean, but only in the latter portion of the tropical cyclone season of December-March. Other basins with significant skill for NTC are the western and eastern North Pacific and Australian basins. The three models have no skill for NTC in the North Indian Ocean.

To check for sensitivity to the chosen verification measure, model skill is also examined using the Spearman rank correlation, Sommer's Delta and Kendall's Tau (Sheskin, 2000). Here we show the results using the model NTC without bias corrections. Results using the bias-corrected NTC (not shown) are similar. For the skill assessments forthcoming, as results generally turn out similarly across the four verification measures, only the correlation skills will be presented. However, the discussions take into account results for all four measures.

\subsection{Tropical cyclone intensity}

Figure 8 shows the average MACE per month in the Southern Hemisphere basins in the models and observations. As the model tropical cyclones do not intensify as much as observed cyclones, the MACE indices in the models have strong amplitude biases. With the exception of the South Indian Ocean (Fig. 8b) where the most active model is ECHAM3, the most active model is ECHAM4. In all basins, the NSIPP model average MACE per month is approximately an order of magnitude smaller than in the two ECHAM models. In the three Southern Hemisphere basins (Australian, South Indian, and South Pacific), the three models reproduce the observed MACE seasonal peak in January-March 
Table 6. Correlations between NTC in the models and observations, by basin, for relevant seasons in the period 1971-2000. Only models and basins with at least one season with significant correlation are shown (total possible number of cells is 168). Bold entries indicate correlation values that have significance at the $95 \%$ confidence level

\begin{tabular}{lrrrrrrrrr}
\hline Basin & Model & MJJ & JJA & JAS & ASO & SON & OND & JJASON & Jan-Dec \\
\hline WNP & ECHAM3 & $\mathbf{0 . 3 7}$ & 0.29 & 0.24 & 0.33 & 0.20 & 0.10 & 0.36 & $\mathbf{0 . 4 0}$ \\
WNP & ECHAM4 & 0.31 & 0.25 & 0.27 & $\mathbf{0 . 4 6}$ & 0.30 & 0.13 & 0.26 & $\mathbf{0 . 5 0}$ \\
ENP & ECHAM4 & $\mathbf{0 . 4 7}$ & $\mathbf{0 . 4 2}$ & 0.33 & $\mathbf{0 . 3 9}$ & 0.29 & 0.10 & $\mathbf{0 . 4 2}$ & $\mathbf{0 . 4 0}$ \\
ATL & ECHAM3 & -0.04 & $\mathbf{0 . 3 9}$ & $\mathbf{0 . 5 6}$ & 0.33 & 0.12 & 0.02 & $\mathbf{0 . 5 3}$ & $\mathbf{0 . 5 5}$ \\
ATL & ECHAM4 & -0.10 & 0.28 & $\mathbf{0 . 4 3}$ & $\mathbf{0 . 4 2}$ & 0.29 & 0.20 & $\mathbf{0 . 5 2}$ & $\mathbf{0 . 5 2}$ \\
ATL & NSIPP & 0.22 & $\mathbf{0 . 5 2}$ & $\mathbf{0 . 3 8}$ & 0.31 & 0.06 & 0.14 & $\mathbf{0 . 3 8}$ & $\mathbf{0 . 4 5}$ \\
& & & & & & & & \\
Basin & Model & NDJ & DJF & JFM & FMA & MAM & AMJ & NDJFMA & Jul-Jun \\
\hline SI & ECHAM4 & 0.00 & 0.05 & 0.05 & 0.31 & $\mathbf{0 . 3 9}$ & $\mathbf{0 . 3 8}$ & 0.21 & 0.14 \\
AUS & ECHAM4 & 0.02 & 0.34 & $\mathbf{0 . 4 3}$ & $\mathbf{0 . 5 1}$ & 0.35 & 0.24 & $\mathbf{0 . 4 1}$ & $\mathbf{0 . 3 8}$ \\
SP & ECHAM3 & $\mathbf{0 . 6 4}$ & $\mathbf{0 . 4 9}$ & $\mathbf{0 . 4 4}$ & $\mathbf{0 . 5 2}$ & $\mathbf{0 . 5 0}$ & $\mathbf{0 . 3 9}$ & $\mathbf{0 . 7 2}$ & $\mathbf{0 . 7 3}$ \\
SP & ECHAM4 & $\mathbf{0 . 5 3}$ & $\mathbf{0 . 4 2}$ & 0.31 & $\mathbf{0 . 3 9}$ & 0.31 & 0.24 & $\mathbf{0 . 5 2}$ & $\mathbf{0 . 6 0}$ \\
SP & NSIPP & 0.36 & 0.34 & $\mathbf{0 . 3 8}$ & $\mathbf{0 . 5 1}$ & $\mathbf{0 . 3 8}$ & 0.00 & $\mathbf{0 . 6 2}$ & $\mathbf{0 . 6 8}$ \\
\hline
\end{tabular}

(a)

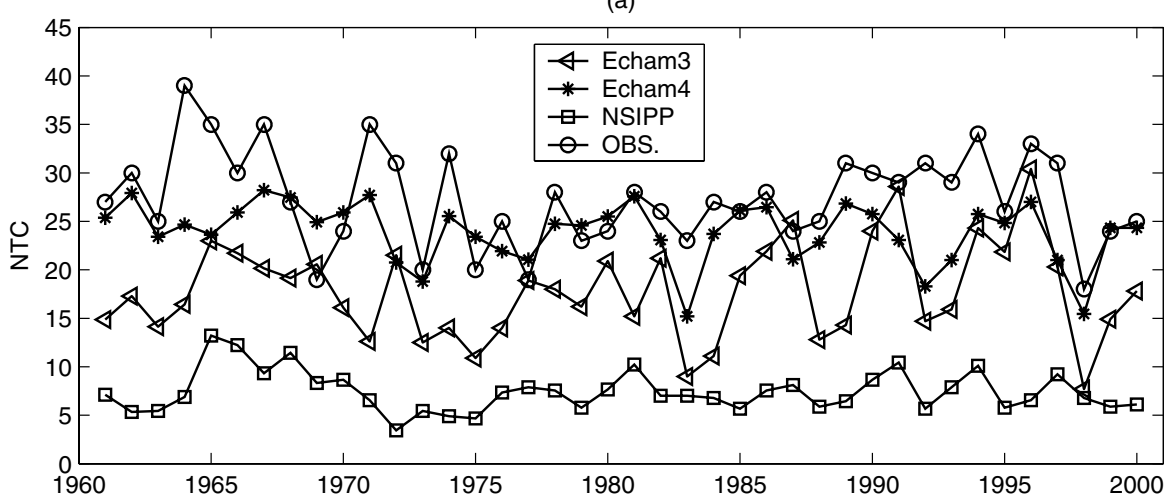

(b)

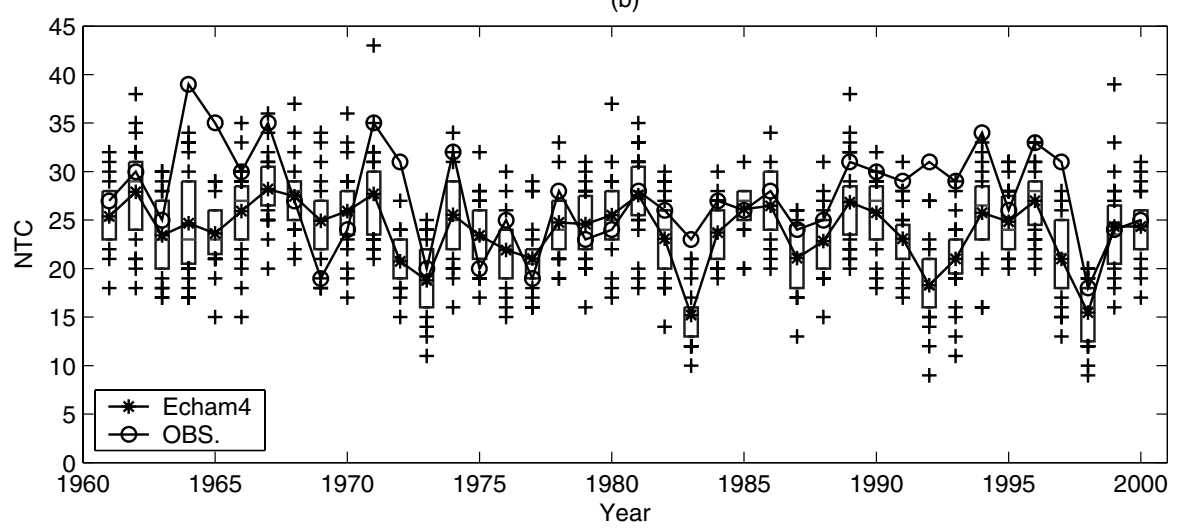

Fig 7. Time series showing the interannual variability of the NTC in the western North Pacific over the period 1961-2000: (a) models (ensemble mean) and observations, (b) ECHAM4 and observations. In (b), ECHAM4 is shown in box plots, which span the 25th to 75th percentiles; the crosses $(+)$ are the ensemble members outside that range and the curve connecting the asterisks $(*)$ shows the ensemble mean in each year. 

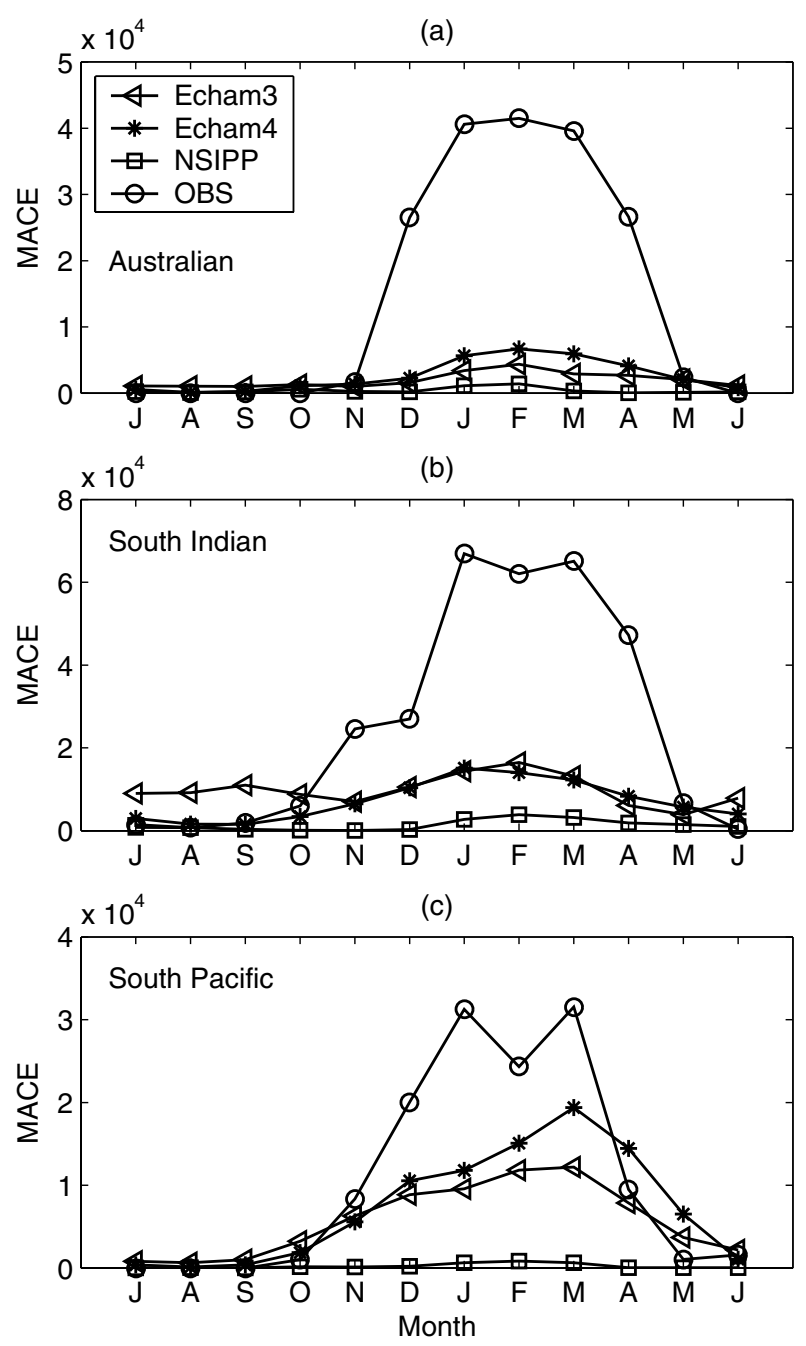

Fig 8. Average MACE per month in the models and observations for (a) the Australian basin, (b) South Indian Ocean, and (c) South Pacific.

(Fig. 8). The models reproduce the MACE annual cycle somewhat better in the Southern Hemisphere than in the Northern Hemisphere.

Figure 9 shows the interannual time series of the ensemble mean model MACE in the western North Pacific and the observed MACE. For the ECHAM4 model, in most years the observed MACE falls within the spread of the bias corrected ensemble members, while for ECHAM3 and NSIPP in many years this does not occur. This may be partly a result of the ECHAM4's greater number of ensemble members ( 24 versus approximately 10). Although none of the model ensemble members captured the observed record MACE in 1997, a few ECHAM3 members approached this level. The model skill for MACE was evaluated using correlations (Table 7) and the additional skill measures described earlier (not shown).
In the South Pacific, correlations for MACE are significant in the ECHAM3 and ECHAM4 models during the tropical cyclone peak season (Table 7), but skill is not significant using the other verification measures. This suggests that a minority of years may dominate in the correlation, as that measure is vulnerable to influence by outliers. Inspection of the data (not shown; see fig. 8 in Camargo et al., 2004) indicates that the relationship is attributable mainly to the warm ENSO years.

\subsection{Tracks centroid}

In some basins, such as the western North Pacific, the average model and observed centroid has a well-defined annual cycle (see Fig. 10). The average north latitude reaches its maximum in August, and most equatorward position around February. Although the model biases in centroid longitude are substantial, they reproduce the latitude-averaged annual cycle quite well, with the exception of NSIPP early in the year.

If the interannual variability of the mean location of tropical cyclone activity is somewhat predictable, this could translate to predictability of year-to-year anomalies in landfall probabilities for defined coastal regions. Interannual variability of mean latitude and longitude differs widely among basins. In the Australian basin there is a much larger standard deviation for the mean longitude $\left(6.7^{\circ}\right)$ than mean latitude $\left(2.8^{\circ}\right)$, while in the North Indian Ocean the standard deviations of latitude and longitude are similar and small $\left(2.6^{\circ}\right.$ and $\left.2.9^{\circ}\right)$. Biases in the model climatological centroid locations were discussed earlier. The models have a reasonable interannual variability of the average latitude in the western North Pacific. Further details on a basin-by-basin basis are available in Camargo et al. (2004).

In Tables 8 and 9 the correlations between the models and observations are shown for the centroid latitude and longitude, respectively. Both ECHAM models have significant skill mainly for the western North Pacific. The tracks centroid location in the eastern North Pacific of ECHAM4 is very similar to that observed, while ECHAM3 has a bias to the west and NSIPP to the east. Significant correlations for centroid longitude also occur in this basin (Table 9). In the South Pacific basin all models have moderately high and significant skill for the centroid latitude, and also in the late season for the centroid longitude.

\section{Conclusions}

Basic statistical aspects of tropical cyclone activity in simulations of three low-resolution AGCMs are examined. The AGCMs are forced by observed SST, and produce ensembles of atmospheric responses. The two main aims are to study the climatologies of model tropical cyclone behavior, and skill in simulating observed interannual variability of aspects of tropical cyclone activity. Despite the low resolution, the models demonstrated significant skill for some tropical cyclone properties on interannual time-scales. Skills are model and basin dependent, and vary among tropical cyclone characteristics. We cannot point to a 
Table 7. Correlations of tropical cyclone activity (MACE) in the bias-corrected models and observations for relevant seasons. The period for western North Pacific, eastern North Pacific, and North Atlantic is 1971-2000; for North Indian, South Indian, Australian and South Pacific, it is 1981-2000. Only models and basins with at least one season of significant correlation are shown (total possible number of cells is 168). Bold entries indicate correlation values having significance at the $90 \%$ confidence level

\begin{tabular}{lrrrrrrrrr}
\hline Basin & Model & MJJ & JJA & JAS & ASO & SON & OND & JJASON & Jan-Dec \\
\hline NI & ECHAM3 & 0.17 & 0.38 & -0.11 & $\mathbf{0 . 7 8}$ & 0.22 & 0.25 & 0.25 & 0.34 \\
WNP & ECHAM3 & $\mathbf{0 . 5 1}$ & $\mathbf{0 . 6 0}$ & $\mathbf{0 . 6 6}$ & $\mathbf{0 . 4 8}$ & $\mathbf{0 . 4 3}$ & 0.22 & $\mathbf{0 . 6 8}$ \\
WNP & ECHAM4 & $\mathbf{0 . 3 3}$ & $\mathbf{0 . 3 1}$ & $\mathbf{0 . 3 9}$ & $\mathbf{0 . 3 4}$ & 0.22 & -0.11 & 0.25 & $\mathbf{0 . 6 5}$ \\
ENP & ECHAM3 & 0.08 & 0.21 & 0.26 & 0.30 & 0.29 & 0.13 & 0.26 \\
ENP & ECHAM4 & $\mathbf{0 . 5 4}$ & $\mathbf{0 . 5 3}$ & $\mathbf{0 . 4 3}$ & $\mathbf{0 . 3 5}$ & 0.23 & 0.03 & $\mathbf{0 . 2 8}$ & $\mathbf{0 . 3 2}$ \\
ATL & ECHAM3 & 0.11 & $\mathbf{0 . 5 2}$ & $\mathbf{0 . 7 7}$ & $\mathbf{0 . 6 1}$ & $\mathbf{0 . 5 1}$ & 0.11 & $\mathbf{0 . 7 2}$ \\
ATL & ECHAM4 & 0.09 & 0.29 & $\mathbf{0 . 6 4}$ & $\mathbf{0 . 5 1}$ & $\mathbf{0 . 4 6}$ & 0.16 & $\mathbf{0 . 5 1}$ & $\mathbf{0 . 7 2}$ \\
ATL & NSIPP & -0.08 & $\mathbf{0 . 3 8}$ & $\mathbf{0 . 6 5}$ & $\mathbf{0 . 6 0}$ & $\mathbf{0 . 4 4}$ & 0.09 & $\mathbf{0 . 5 9}$ \\
& & & & & & & & $\mathbf{0 . 5 8}$ \\
Basin & Model & NDJ & DJF & JFM & FMA & MAM & AMJ & NDJFMA & Jul-Jun \\
\hline SI & ECHAM3 & $\mathbf{0 . 5 7}$ & $\mathbf{0 . 4 8}$ & 0.27 & 0.08 & 0.03 & $\mathbf{0 . 5 1}$ & $\mathbf{0 . 5 2}$ & $\mathbf{0 . 6 0}$ \\
AUS & NSIPP & -0.09 & -0.31 & -0.23 & 0.30 & $\mathbf{0 . 5 9}$ & $\mathbf{0 . 4 8}$ & -0.14 & -0.17 \\
SP & ECHAM3 & $\mathbf{0 . 6 0}$ & $\mathbf{0 . 4 8}$ & $\mathbf{0 . 4 8}$ & $\mathbf{0 . 4 6}$ & $\mathbf{0 . 4 5}$ & 0.23 & $\mathbf{0 . 6 7}$ & $\mathbf{0 . 6 7}$ \\
SP & ECHAM4 & $\mathbf{0 . 6 0}$ & $\mathbf{0 . 4 7}$ & $\mathbf{0 . 4 6}$ & 0.27 & 0.28 & 0.20 & $\mathbf{0 . 6 2}$ & $\mathbf{0 . 6 5}$ \\
SP & NSIPP & $\mathbf{0 . 4 5}$ & 0.30 & 0.33 & $\mathbf{0 . 5 4}$ & $\mathbf{0 . 5 4}$ & $\mathbf{0 . 5 8}$ & $\mathbf{0 . 5 7}$ & $\mathbf{0 . 6 1}$ \\
\hline
\end{tabular}

Fig 9. Time series of tropical cyclone activity (MACE) in the bias corrected models (ensemble mean) and observations in the western North Pacific over the period 1961-2000.

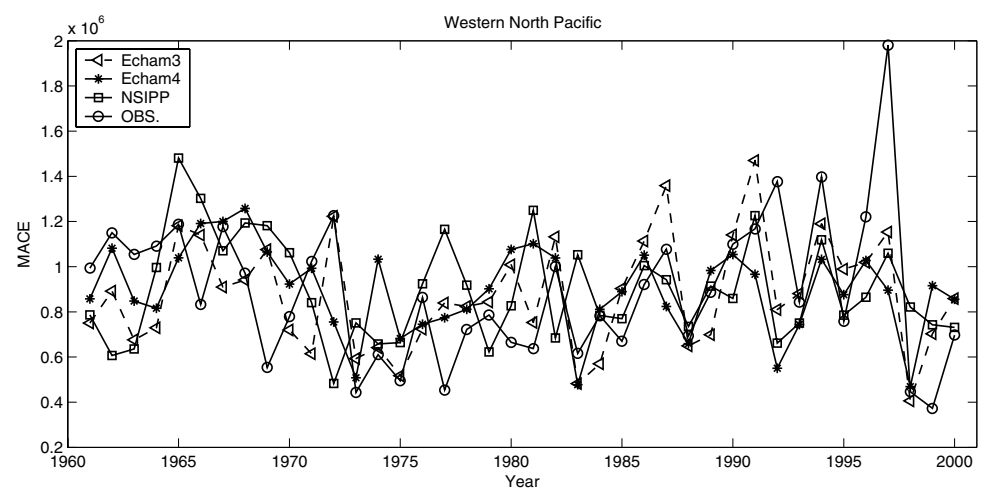

Fig 10. Average centroid locations by month in the western North Pacific in the models and observations. The locations representing the months of January, April, July, and October are denoted by symbols of progressively increasing size.

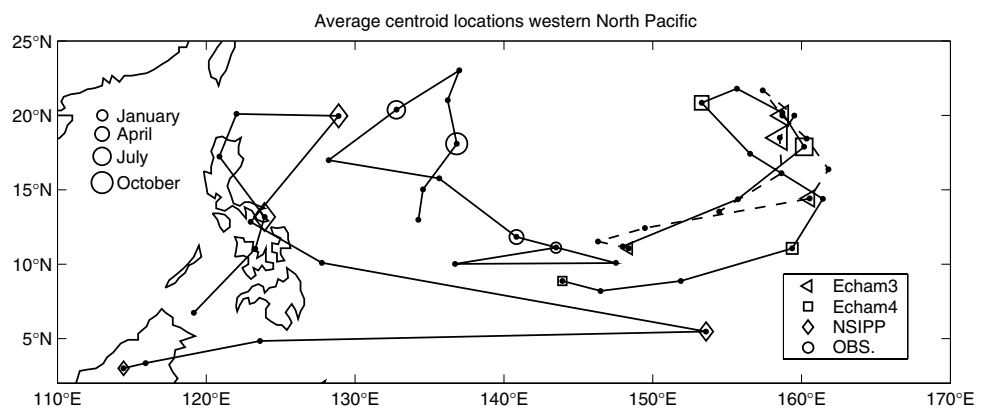

single model as having the best skill across the different tropical cyclone variables globally.

The tropical cyclone activity in all models occurs nearer the equator than in observations. All models have low simulation skill in the Indian Ocean, both south and north of the equator. In the North Indian Ocean, even the tropical cyclone activity annual cycle is poorly simulated, likely due to failure to reproduce the inhibiting effect of the summer monsoon and the consequent 
Table 8. Correlations of the average latitude of tropical cyclone tracks in the models with observations, by basin for different seasons in the period 1971-2000. Years without tropical cyclones are omitted by model, season, and basin. Only models and basins with at least one season with significant correlation are shown (total possible number of cells is 168). Bold entries indicate correlation values having significance at the $95 \%$ confidence level

\begin{tabular}{|c|c|c|c|c|c|c|c|c|c|}
\hline Basin & Model & MJJ & JJA & JAS & ASO & SON & OND & JJASON & Jan-Dec \\
\hline NI & ECHAM4 & -0.05 & -0.06 & -0.43 & -0.24 & 0.16 & 0.51 & -0.09 & -0.08 \\
\hline WNP & ECHAM3 & 0.21 & 0.61 & 0.56 & 0.39 & 0.07 & 0.10 & 0.36 & 0.54 \\
\hline WNP & ECHAM4 & 0.50 & 0.68 & 0.70 & 0.43 & 0.11 & 0.21 & 0.54 & 0.56 \\
\hline ENP & NSIPP & 0.00 & 0.36 & 0.79 & 0.13 & 0.25 & 0.20 & 0.17 & 0.14 \\
\hline Basin & Model & NDJ & DJF & JFM & FMA & MAM & AMJ & NDJFMA & Jul-Jun \\
\hline AUS & ECHAM4 & 0.26 & 0.37 & 0.30 & 0.27 & 0.42 & 0.20 & 0.47 & 0.60 \\
\hline SP & ECHAM3 & 0.43 & 0.42 & 0.50 & 0.44 & 0.42 & 0.31 & 0.52 & 0.58 \\
\hline SP & ECHAM4 & 0.78 & 0.86 & 0.83 & 0.80 & 0.51 & 0.01 & 0.90 & 0.90 \\
\hline SP & NSIPP & 0.50 & 0.66 & 0.70 & 0.64 & -0.12 & -0.33 & 0.72 & 0.65 \\
\hline
\end{tabular}

Table 9. Correlations of the average longitude of tropical cyclone tracks in the models with observations, by basin for different seasons in the period 1971-2000. Years without tropical cyclones are omitted by model, season, and basin. Only models and basins with at least one season with significant correlation are shown (total possible number of cells is 168). Bold entries indicate correlation values having significance at the $95 \%$ confidence level

\begin{tabular}{lrrrrrrrrr}
\hline Basin & Model & MJJ & JJA & JAS & ASO & SON & OND & JJASON & Jan-Dec \\
\hline NI & ECHAM4 & -0.33 & -0.01 & -0.04 & 0.11 & -0.13 & 0.06 & 0.29 \\
WNP & ECHAM3 & -0.08 & -0.04 & 0.10 & 0.35 & $\mathbf{0 . 5 7}$ & $\mathbf{0 . 6 3}$ & $\mathbf{0 . 4 5}$ \\
WNP & ECHAM4 & 0.35 & 0.20 & 0.18 & $\mathbf{0 . 3 9}$ & $\mathbf{0 . 6 1}$ & $\mathbf{0 . 7 9}$ & $\mathbf{0 . 5 8}$ \\
WNP & NSIPP & 0.18 & 0.16 & 0.09 & $\mathbf{0 . 4 3}$ & $\mathbf{0 . 4 6}$ & 0.32 & $\mathbf{0 . 5 1}$ \\
ENP & ECHAM3 & 0.15 & 0.25 & $\mathbf{0 . 4 3}$ & 0.29 & 0.12 & -0.14 & $\mathbf{0 . 4 3}$ \\
ENP & ECHAM4 & -0.18 & 0.33 & $\mathbf{0 . 3 6}$ & 0.32 & -0.03 & -0.22 & 0.34 & $\mathbf{0 . 4 8}$ \\
& & & & & & & & \\
Basin & Model & NDJ & DJF & JFM & FMA & MAM & AMJ & NDJFMA & Jul-Dec \\
\hline SP & ECHAM3 & 0.20 & -0.02 & 0.07 & 0.27 & $\mathbf{0 . 3 9}$ & $\mathbf{0 . 5 3}$ & 0.31 \\
SP & ECHAM4 & $\mathbf{0 . 4 1}$ & 0.16 & 0.25 & 0.35 & $\mathbf{0 . 4 4}$ & $\mathbf{0 . 5 3}$ & 0.35 \\
SP & NSIPP & -0.16 & -0.09 & -0.11 & 0.22 & 0.14 & $\mathbf{0 . 5 2}$ & 0.13 & 0.34 \\
\hline
\end{tabular}

bimodal observed annual cyclone cycle. ${ }^{5}$ For NTC, all models have significant interannual simulation skill in the South Pacific and the Atlantic. This may be due to a strong relationship with the ENSO in these two basins. The Atlantic and western North Pacific are the basins where the models demonstrate significant skills for most variables. Lesser skill in the South Pacific for variables other than NTC may be due to relatively questionable data quality there, which would have least impact on NTC.

Although the tropical cyclones of the models are considerably weaker than those observed, the model MACE indices are significantly correlated with those observed in some basins. In the

${ }^{5}$ Proper simulation of the monsoon is difficult without using a fully coupled ocean-atmosphere model to reproduce atmosphere-to-ocean feedbacks known to play a key role in monsoon dynamics (e.g. Wang et al., 2004; Kumar et al., 2005). eastern North Pacific, for instance, the ECHAM4 model does not have significant skill in the peak season (JAS) for NTC, but has significant skill in that season for the MACE index.

Overall, ECHAM4 is the model with the most significant skill across the different properties, especially in the western North Pacific and the South Pacific. ECHAM3 has generally better skill in the Atlantic than the other models. NSIPP has very different characteristics in the Southern Hemisphere versus the Northern Hemisphere, being more similar to observations in the Southern Hemisphere. Although NSIPP has a slightly higher numerical resolution than both ECHAM models, this does not appear to translate to better simulated tropical cyclone activity characteristics, perhaps because other factors are of equal importance, such as physical parametrization schemes (Vitart and Stockdale, 2001). For the cyclone genesis density pattern, the NSIPP model represents reality better than the other two models. 
Many of the deficiencies of these AGCMs are due to the low resolution used in this study. By increasing the resolution of the ECHAM3 model and comparing with a low-resolution version of the same model, increasingly more realistic model tropical cyclones were created (Bengtsson et al., 1982, 1995). Clearly, some of the model biases discussed here, such as the low number of tropical cyclones and the closeness to the equator, could be greatly reduced by using higher-resolution models. However, as mentioned above, resolution is but one of several major factors impacting model performance. Given that it is still very costly to run operationally ensembles of AGCMS at high resolution, the intercomparison of low-resolution AGCM performance for tropical cyclones, as carried out here, is of high interest if these models are to be used in operational forecasts of seasonal tropical cyclone activity, as is the case at IRI (Experimental Tropical Cyclone Activity Forecasts available on-line at http://iri.columbia.edu/forecast/tc_fcst/).

The ECHAM3 and ECHAM4 models have very long tracks in the Southern Hemisphere compared to the observations, and this is reflected in long cyclone lifetimes. Although the NSIPP model tropical cyclones have shorter tracks in the Southern Hemisphere, the lifetimes are even longer, reflecting NSIPP's very slow cyclone movement. Examination indicates that this slowness is not due to NSIPP's mean flow, as the wind speed at several levels appears realistic (Bacmeister et al., 2000). Rather, it may be related to the mechanical aspects related to the NSIPP model output data, such as the fact that, in contrast to the ECHAM models, we computed vorticity ourselves from the wind components (it is not standard output), and the temporal resolution is once daily rather than four times daily. Both of these factors could tend to smooth and dilute the vorticity field.

In summary, some aspects of the observed tropical cyclone activity are reproduced by the models fairly well, both in terms of model climatology and interannual variability. In some cases, biases in model climatology do not preclude simulation skill for interannual variability, as for instance in the Atlantic. Other aspects of cyclone behavior have significantly greater problems and may still be handled most effectively by statistical tools at this point, such as tropical cyclone numbers by strength category. Overall, simulation skills realized here do not surpass those of statistical models, and in some cases are somewhat lower. However, given the low resolution of the models, these results may be viewed as encouraging in the context of what might be possible using improved versions of these dynamical tools. The interannual variability of simulations of many of the variables is statistically significantly correlated with observations. Statistical significance, however, does not necessarily imply high practical utility. For some parameters, improved dynamical representations may improve future simulation quality to the point of being able to provide useful forecasts of probability anomaly of cyclone landfall along designated coastlines.

The relation between model tropical cyclone characteristics and ENSO is currently being examined.

\section{Acknowledgments}

The authors thank Dr Max Suarez and Michael Kistler (NSIPP) for making the NSIPP model data available, and Max-PlanckInstitute for Meteorology (Hamburg, Germany) for making both versions of their model ECHAM accessible. We thank Dr Simon Mason for suggestions on statistical measures and comments on the study, and Dr Lisa Goddard for helpful discussions about the results. We are indebted to Dr Benno Blumenthal for the IRI Data Library and Drs Michael Tippett, Andrew Robertson and Adam Sobel for insightful comments on this paper.

\section{References}

Arpe, K., Dümenil, L. and Giorgetta, M. A. 1998. Variability of the Indian monsoon in the ECHAM3 model: sensitivity to sea surface temperature, soil moisture and the stratospheric quasi-biennial oscillation. J. Clim. 11, 1837-1858.

Avila, L. A., Pasch, R. J., Beven, J. L., Franklin, J. L., Lawrence, M. B. and co-authors. 2003. Eastern North Pacific hurricane season of 2001. Mon. Wea. Rev. 131, 249-262.

Bacmeister J., Pegion, P. J., Schubert, S. D. and Suarez, M. J. 2000. Atlas of Seasonal Means Simulated by the NSIPP 1 Atmospheric GCM. Technical Report Series on Global Modelling and Data Assimilation, NASA Technical Memorandum 104606, Vol. 17, Goddard Space Flight Center, Greenbelt, MD, USA, 194 pp.

Barnston, A. G., Mason, S. J., Goddard, L., DeWitt, D. G. and Zebiak, S. E. 2003. Multimodel ensembling in seasonal climate forecasting at IRI. Bull. Am. Meteorol. Soc. 84, 1783-1796.

Bell, G. D., Halpert, M. S., Schnell, R. C., Higgins, R. W., Lawrimore, J. and co-authors. 2000. Climate assessment for 1999. Bull. Am. Meteorol. Soc. 81, S1-S50.

Bengtsson, L. 2001. Hurricane threats. Science 293, 440-441.

Bengtsson, L., Böttger, H. and Kanamitsu, M. 1982. Simulation of hurricane-type vortices in a general circulation model. Tellus 34, 440457.

Bengtsson, L., Botzet, M. and Esch, M. 1995. Hurricane-type vortices in a general circulation model. Tellus 47A, 175-196.

Bengtsson, L., Botzet, M. and Esch, M. 1996. Will greenhouse gasinduced warming over the next 50 years lead to higher frequency and greater intensity of hurricanes? Tellus $\mathbf{4 8 A}$, 57-73.

Broccoli, A. J. and Manabe, S. 1990. Can existing climate models be used to study anthropogenic changes in tropical cyclone climate? Geophys. Rev. Lett. 17, 1917-1920.

Camargo, S. J. and Sobel, A. H. 2004. Formation of tropical storms in an atmospheric general circulation model. Tellus 56 A, 56-67.

Camargo, S. J. and Zebiak, S. E. 2002. Improving the detection and tracking of tropical storms in atmospheric general circulation models. Wea. Forecasting 17, 1152-1162.

Camargo, S. J., Barnston, A. G. and Zebiak, S. E. 2004. Properties of tropical cyclones in atmospheric general circulation models. IRI Technical Report 04-02, International Research Institute for Climate Prediction, Palisades, NY, USA, 72 pp.

Chan, J. C. L., Shi, J. E. and Lam, C. M. 1998. Seasonal forecasting of tropical cyclone activity over the western North Pacific and the South China Sea. Wea. Forecasting 13, 997-1004. 
Cherchi, A. and Navarra, A. 2003. Reproducibility and predictability of the Asian summer monsoon in the ECHAM4-GCM. Clim. Dyn. 20, 365-379.

Emanuel, K. 2003. Tropical Cyclones. Ann. Rev. Earth Planet. Sci. 31, 75-104.

Franklin, J. L., Avila, L. A., Beven, J. L., Lawrence, M. B., Pasch, R. J. and co-authors. 2003. Eastern North Pacific hurricane season of 2002. Mon. Wea. Rev. 131, 2379-2393.

Goddard, L., Mason, S. J., Zebiak, S. E., Ropelewski, C. F., Basher, R. E. and co-authors. 2001. Current approaches to seasonal to interannual climate predictions. Int. J. Climatol. 21, 1111-1152.

Goddard, L., Barnston, A. G. and Mason, S. J. 2003. Evaluation of the IRI's "Net Assessment" seasonal climate forecasts: 1997-2001. Bull. Am. Meteorol. Soc. 84, 1761-1781.

Gray, W. M., Landsea, C. W., Mielke, P. W. Jr and Berry, K. J. 1993. Predicting Atlantic basin seasonal tropical cyclone activity by 1 August. Wea. Forecasting 8, 73-86.

Gray, W. M., Landsea, C. W., Mielke, P. W. Jr and Berry, K. J. 1994. Predicting Atlantic basin seasonal tropical cyclone activity by 1 June. Wea. Forecasting 9, 103-115.

Haarsma, R. J., Mitchell, J. F. B. and Senior, C. A. 1993. Tropical disturbances in a GCM. Clim. Dyn. 8, 247-257.

Krishnamurti, T. N. 1988. Some recent results on numerical weather prediction over the tropics. Aust. Meteorol. Mag. 36, 141-170.

Krishnamurti, T. N., Oosterhof, D. and Dignon, N. 1989. Hurricane prediction with a high resolution global model. Mon. Wea. Rev. 117, 631-669.

Kumar, K., Hoerling, M. and Rajagopalan, B. 2005. Advancing Indian monsoon rainfall predictions. Geophys. Res. Lett. 32, L08704, doi:10.1029/2004GL021979.

Lal, M., Cubasch, U., Perlwitz, J. and Waszkewitz, J. 1997. Simulation of the Indian monsoon climatology in ECHAM3 climate model: sensitivity to horizontal resolution. Int. J. Clim. 17, 847-858.

Landman, W. A., Seth, A. and Camargo, S. J. 2005. The effect of regional climate model domain choice on the simulation of tropical cyclonelike vortices in the southwestern Indian ocean. J. Climate 18, 12631274.

Liu, K. S. and Chan, J. C. L. 2003. Climatological characteristics and seasonal forecasting of tropical cyclones making landfall along the South China coast. Mon. Wea. Rev. 131, 1650-1662.

Manabe, S., Holloway, J. L. and Stone, H. M. 1970. Tropical circulation in a time-integration of a global model of the atmosphere. J. Atmos. Sci. 27, 580-613.

Mason, S. J., Goddard, L., Graham, N. E., Yulaeva, E., Sun, L. Q. and co-authors. 1999. The IRI seasonal climate prediction system and the 1997/98 El Niño event. Bull. Am. Meteorol. Soc. 80, 1853-1873.

May, W. H. 2003. The Indian summer monsoon and its sensitivity to the mean SSTs: simulations with the ECHAM4 AGCM at T106 horizontal resolution. J. Meteorol. Soc. Japan 81, 57-83.

Model User Support Group. 1992. Echam3 - atmospheric general circulation model. Technical Report 6, Das Deutshes Klimarechnenzentrum, Hamburg, Germany, 184 pp.

Moorthi, S. and Suarez, M. J. 1992. Relaxed Arakawa-Schubert: a parametrization of moist convection for general circulation models. Mon. Wea. Rev. 120, 978-1002.
Roeckner, E., Arpe, K., Bengtsson, L., Christoph, M., Claussen, M. and co-authors. 1996. The atmospheric general circulation model ECHAM-4: model description and simulation of present-day climate. Technical Report 218, Max-Planck-Institute for Meteorology, Hamburg, Germany, 90 pp.

Royer, J.-F., Chauvin, F., Timbal, B., Araspin, P. and Grimal, D. 1998. A GCM study of the impact of greenhouse gas increase on the frequency of occurrence of tropical cyclones. Clim. Change 38, 307-343.

Ryan, B. F., Watterson, I. G. and Evans, J. L. 1992. Tropical cyclone frequencies inferred from Gray's yearly genesis parameter: validation of GCM tropical climate. Geophys. Res. Lett. 19, 1831-1834.

Sheskin, D. J. 2000. Handbook of Parametric and Non-parametric Statistical Procedures, 2nd edition. Chapman \& Hall/CRC, Boca Raton, FL, USA.

Suarez, M. J. and Takacs, L. L. 1995. Documentation of the Aries/GEOS dynamical core: Version 2. Technical Report Series on Global Modelling and Data Assimilation, NASA Technical Memorandum 104606, Vol. 5, Goddard Space Flight Center, Greenbelt, MD, USA, 58 pp.

Sugi, M., Noda, A. and Sato, N. 2002. Influence of global warming on tropical cyclone climatology: an experiment with the JMA global model. J. Meteorol. Soc. Japan 80, 249-272.

Thorncroft, C. and Pytharoulis, I. 2001. A dynamical approach to seasonal prediction of Atlantic tropical cyclone activity. Wea. Forecasting 16, 725-734.

Tiedtke, M. 1989. A comprehensive mass flux scheme for cumulus parametrization in large-scale models. Mon. Wea. Rev. 117, 17791800.

Tsutsui, J. I. and Kasahara, A. 1996. Simulated tropical cyclones using the National Center for Atmospheric Research community climate model. J. Geophys. Res. 101, 15013-15032.

Vitart, F. D. and Stockdale, T. N. 2001. Seasonal forecasting of tropical storms using coupled GCM integrations. Mon. Wea. Rev. 129, 25212537.

Vitart, F., Anderson, J. L. and Stern, W. F. 1997. Simulation of interannual variability of tropical storm frequency in an ensemble of GCM integrations. J. Climate 10, 745-760.

Vitart, F., Anderson, J. L. and Stern, W. F. 1999. Impact of large-scale circulation on tropical storm frequency, intensity and location, simulated by an ensemble of GCM Integrations. J. Climate 12, 32373254.

Vitart, F., Anderson, D. and Stockdale, T. 2003. Seasonal forecasting of tropical cyclone landfall over Mozambique. J. Climate 16, 39323945.

Walsh, K. J. E. and Ryan, B. F. 2000. Tropical cyclone intensity increase near Australia as a result of climate change. J. Climate 13, 30293036.

Wang, B., Kang, I. S. and Lee, J. Y. 2004. Ensemble simulations of Asian-Australian monsoon variability by 11 AGCMs. J. Climate 17, 803-818.

Watterson, I. G., Evans, J. L. and Ryan, B. F. 1995. Seasonal and interannual variability of tropical cyclogenesis: diagnostics from large-scale fields. J. Climate 8, 3052-3066.

Wu, G. and Lau, N. C. 1992. A GCM Simulation of the relationship between tropical storm formation and ENSO. Mon. Wea. Rev. 120, 958-977. 